\title{
EVOLUÇÃO GEOTECTÔNICA DA PORÇÃO NE DE SANTA CATARINA E SE DO PARANÁ, COM BASE EM INTERPRETAÇÕES GEOCRONOLÓGICAS
}

\author{
OSWALDO SIGA JÚNIOR*, MIGUEL A.S. BASEI* e ADILSON MACHIAVELLI**
}

\begin{abstract}
GEOTECTONIC EVOLUTION OF NORTHEASTERN SANTA CATARINA AND SOUTHEASTERN PARANA, BASED ON GEOCHRONOLOGICAL INTERPRETATION. This paper discusses the geotectonic evolution of Precambrian terranes in southeastern Paraná and northeastem Santa Catarina. Lithological, petrographical, structural, geochemical and main geochronological differences in this region allow three large geotectonic domains with independent evolution to be defined. The southern Luís Alves domain contains granulite fácies rocks with Archean (2,750-2,850 Ma) and Paleoproterozoic $(2,250-$ $1,850 \mathrm{Ma}$ ) ages. These rocks are believed to represent the continental part of a microplate, sandwiched between the African Congo and Brazilian Paraná cratons during the Neoproterozoic. The northern Curitiba domain is composed of amphibolite fácies gneiss-migmatites accompanied by deformed granitoids. The mesosomes have Paleoproterozoic $(2,150-1,800 \mathrm{Ma})$ formation ages, while leucosomes and granites were formed during the Neoproterozoic (720-550 Ma). The Costeiro domain occupies part of the eastern sector of the region and is mainly composed of foliated calc-alkaline granites of Neoproterozoic (615-570 Ma) age. The Luis Alves and Curitiba domains were sites for important alkaline-peralkaline granite intrusion at 600-550 Ma, and for intense intermediate-acid volcanism (520-480 Ma) associated with the installation of molasse basins. These basins formed as a result of crustal rearrangement during lithospheric thickening produced by continental collisions from Neoproterozoic to Cambrían times.
\end{abstract}

Keywords: Microplate, collision, crustal reworking.

\begin{abstract}
RESUMO O objetivo deste trabalho é discutir a evolução geotectônica de terrenos pré-cambrianos localizados na porção nordeste de Santa Catarina e sudeste do Paraná. As diferenças litológicas, petrográficas, estruturais e geoquímicas, acopladas principalmente aos estudos geocronológicos, permitiram reconhecer neste setor a existência de três grandes domínios geotectônicos, com evoluções próprias e distintas. O primeiro domínio (Luis Alves) localiza-se na porção meridional da área, sendo representado por rochas da fácies granulito, com idades de formação relativas ao Arqueano (2.720-2.580 Ma) e ao Paleoproterozóico (2.250$1.850 \mathrm{Ma}$ ). Do ponto de vista geotectônico, esses terrenos foram interpretados como representantes da porção continental de uma microplaca, localizada entre os Cratons do Congo (Africa) e do Paraná (Brasil), no Neoproterozóico. No segundo domínio (Curitiba), ocorrem rochas gnáissico-migmatíticas, da fácies anfibolito, associadas a granitóides deformados, distribuídos ao longo de toda porção setentrional estudada. Caracterizase por mesossomas formados no Paleoproterozóico $(2.150-1.800 \mathrm{Ma})$, com leucossomas e porções graníticas do Neoproterozóico (720-550 Ma). Os dados geológicos e geocronológicos sugerem tratar-se de zona de borda da mesma Microplaca Luis Alves, intensamente deformada no Neoproterozóico (Ciclo Brasiliano). O terceiro domínio (Costeiro) ocupa parte do setor oriental, sendo representado, principalmente, por granitóides cálcio-alcalinos foliados, gerados no Neoproterozóico (615-570 Ma). Adicionalmente, nos Terrenos Luis Alves e Curitiba, ocorre importante granitogênese alcalina-peralcalina (600-550 Ma), bem como intenso vulcanismo ácido-intermediário (520-480 Ma) associado à evolução das bacias molássicas, consequência do rearranjo crustal, decorrente do espessamento litosférico produzido pelas colisões continentais que ocorreram no Neoproterozóico com continuidade até o Cambriano.
\end{abstract}

Palavras-chave: Microplaca, colisão, retrabalhamento crustal.

INTRODUĈ̃̃O Este trabalho tem por objetivo discutir a evolução geotectônica de terrenos pré-cambrianos localizados na porção sudeste paranaense e nordeste catarinense, tendo como enfoque principal a análise dos dados geocronológicos disponíveis (Fig. 1).

Trata-se de terrenos que foram caracterizados por alguns autores (Carneiro 1974, Hasui et al. 1975, Kaul 1975 etc.) como entidades antigas, relativamente estáveis, ao lado das quais se desenvolveram os cinturões de dobramento Ribeira (a noroeste) e Dom Feliciano (a sudeste). Ao serem iniciados os estudos neste setor, tais hipoteses pareciam viáveis no que se refere à geotectônica, e a ideia básica era a de melhor definir esta porção cratônica, principalmente no tocante a seus limites e padrão geocronológico.

Os inúmeros perfis geológicos realizados, envolvendo aspectos litológicos, petrográficos, estruturais, geoquímicos $\mathrm{e}$, principalmente, geocronológicos, acoplados aos dados gravimétricos, mostraram a existência de três domínios com evoluções próprias e distintas.

O primeiro (Domínio Luis Alves) é representado predominantemente por rochas gnáissico-granulíticas, que tem sua maior expressão no setor sul da região estudada (Barra Velha, Luis Alves, São Bento do Sul), estendendo-se de modo contínuo para nordeste, onde apresenta-se bastante afilado, entre os domínios adjacentes.

$\mathrm{O}$ segundo (Domínio Curitiba) distribui-se por toda porção nordeste da área (Piên, Curitiba, Quatro Barras), sendo representado principalmente por gnaisses bandados, gnaisses graníticos e migmatitos.

No terceiro (Domínio Costeiro) predominam granitóides cálcio-alcalinos foliados que ocupam grande parte da porção oriental estudada (São Francisco do Sul - SC, Paranaguá e Guaraqueçaba - PR).

Adicionalmente, ocorre nesses domínios expressiva granitogênese de natureza alcalina-peralcalina (Suíte Serra do Mar - Kaul 1984), bem como intenso vulcanismo ácidointermediário associado à evolução das bacias molássicas de Campo Alegre, Guaratubinha e Corupá.

Geotectônicamente, esses terrenos foram denominados por Basei et al (1992b), respectivamente de Microplaca Luis Alves, Microplaca Curitiba e Cinturão Granitóide Costeiro, modificando propostas anteriores apresentadas por Basei et al (1991) e Basei et al (1992a).

\footnotetext{
* Departamento de Geologia Geral, Instituto de Geociências, Universidade de São Paulo, Caixa Postal 11348, CEP 05422-970, São Paulo, SP, Brasil ** Departamento de Geociências, Centro de Ciências Exatas, Universidade Estadual de Londrina, Caixa Postal 6001, CEP 86051-970, Londrina, PR, Brasil
} 


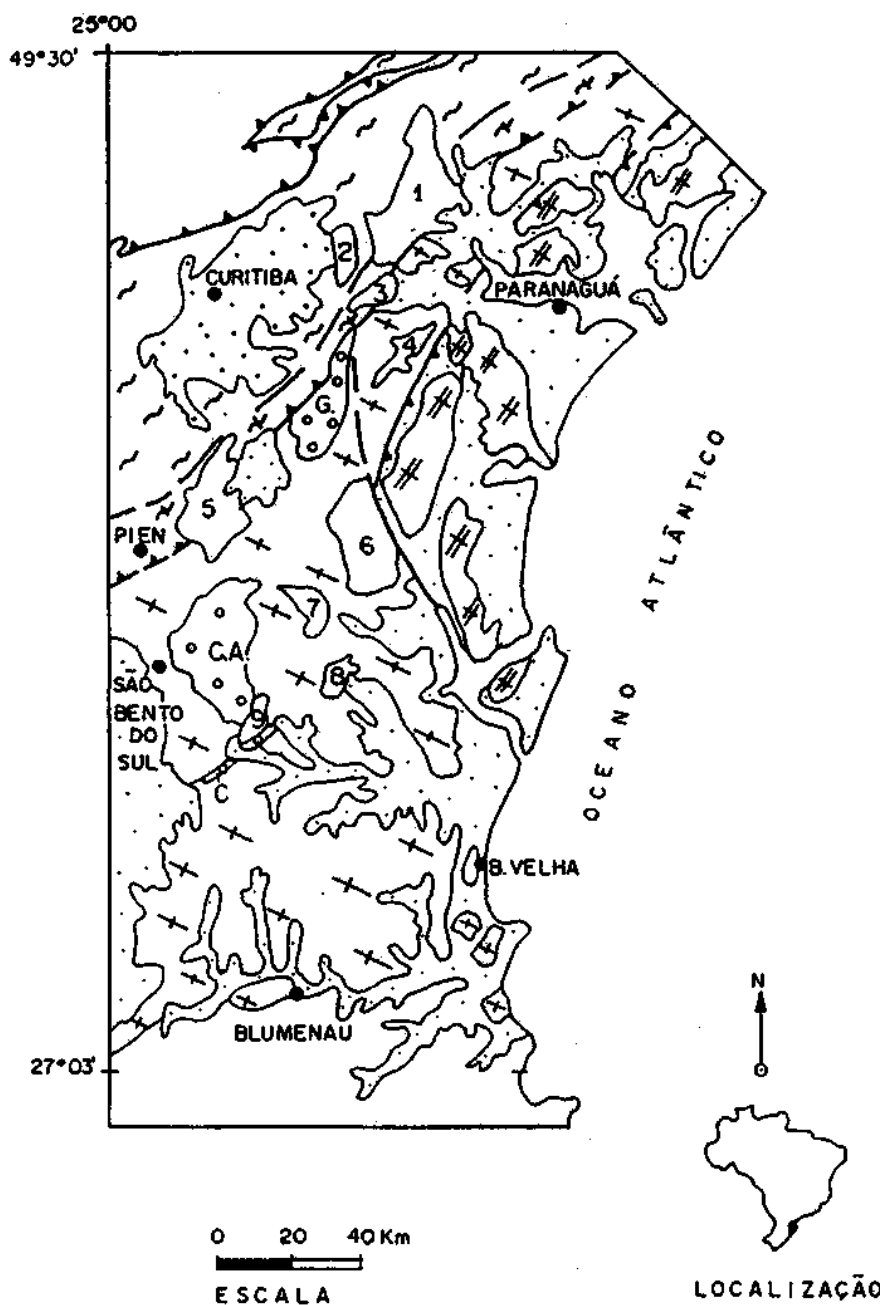

Depósitos cenozóicos e cobertura paleozóica da bacia do Paraná

\section{Ciaturóes de Dobramentos}

प Sequêtencias meta-vulcanossedimentares: grupos Açungui, Setuva, (Cinturảo Ribeira-Norte) / Itajar, Brusque (Cinturão Dom Feliciano-Sul)

Terrenos Intermediários aos Cinturöes

0. Bacias molássicas: C.A. - Campo Alegre, G-Guaratubinha, CCorupá

1 Granitos intrusivos: 1 - Graciosa, 2 - Anhangava, 3 - Marumbi, 4 - Serra da Igreja, 5 - Agudos, 6 - Morro Redondo, 7 - Dona Francisca, 8 - Piral, 9 - Corupá

\section{Domínio Curitiba}

- Gnaisses Bandados, migmatitos., anfibolitos

++ Granitoides calcio-alcalinos deformados

\section{Dominio Costeiro}

Granitóides porfíríticos cálcio-alcalinos, xistos, gnaisses, granitos leucográticos

\section{Domínio Luis Alves}

$x$ Gnaisses Granulfiticos quartzo-feldsfáticos com intercalaçðes de corpos máfico-ultramáficos, quartzitos, formaçōes ferrfferas, paragnaisses

Figura 1 - Compartimentação tectônica da porção $S E$ do Paraná e NE de Santa Catarina

Figure 1 - Tectonic framework of SE Parana and NE Santa Catarina, Brazil
O termo microplaca aqui utilizado representa pequenas placas, isto é, fragmentos crustais menores que $10^{6} \mathrm{~km}^{2}$, que apresentam pelo menos uma margem ativa, conforme proposição de Condie (1989).

São disponíveis mais de 600 determinações isotópicas obtidas pêlos métodos Sm-Nd (minerais e rocha total); U-Pb (zircões); $\mathrm{Pb}-\mathrm{Pb}$ (feldspatos e rocha total); $\mathrm{Rb}-\mathrm{Sr}$ (minerais e rocha total) e $\mathrm{K}-\mathrm{Ar}$ (minerais), que em muito contribuíram para o entendimento da evolução geotectônica desses terrenos. A grande maioria destes dados são ainda inéditos (Siga Jr., tese em preparação), incluindo adicionalmente os obtidos por outros autores, a exemplo de Minioli (1972), Girardi (1974), Hartmann et al (1979), Kaul \& Teixeira (1982), Basei (1985), Basei et al. (1990), Machiavelli et al (1991), Hartmann et al (submitted for publication), reinterpretados neste trabalho.

QUADRO GEOLÓGICO-GEOCRONOLÓGICO Os

três grandes segmentos geotectônicos que compõem o setor SE paranaense e NE catarinense encontram-se representados na figura 1. Este artigo discutirá, de modo sucinto, cada um desses compartimentos, bem como os maciços graníticos intrusivos, e sequências vulcano-sedimentares que compõem as bacias molássicas, com ênfase na evolução geocronológica dos mesmos.

Domínio Luis Alves Limita-se, na porção setentrional, com os gnaisses graníticos do Domínio Curitiba; na porção oriental, em parte atinge a costa brasileira e em parte é balizado pelo Domínio Costeiro; e, na porção meridional, faz contato com o Cinturão Dom Feliciano. Esses limites estão, em parte, relacionados a falhas de empurrão que colocam os terrenos adjacentes por sobre os gnaisses granulíticos do Domínio Luis Alves.

Litologicamente, esses terrenos são representados por gnaisses granulíticos, bandados a maciços, de composição tonalito-granodiorítica com frequentes variações a granulitos básicos. Ocorrem adicionalmente ultramafitos, quartzitos, gnaisses kinzigíticos, formações ferríferas, milonitognaisses granulíticos e migmatitos.

Petrograficamente, observa-se nos gnaisses granulíticos a presença de quartzo, plagioclásio (oligoclásio-andesina), hiperstênio, diopsídio, hornblenda (verde amarronada), biotita titanífera (marrom-avermelhada) e, mais raramente, granada. Como acessórios, são comuns o zircão, apatita, rutilo e minerais opacos. O fácies granulito é caracterizado pela presença de hiperstênio. A ocorrência de hornblenda em coroas de reação nos piroxênios sugere retrometamorfismo da fácies anfibolito. Localmente, próximo às zonas de cisalhamento, ocorrem epídoto e clorita, denotando um evento retrometamórfico da fácies xisto-verde.

A orientação do bandamento nesses gnaisses granulíticos é francamente NW, diferente do padrão NE dos demais domínios. Este bandamento, uma superfície $\mathrm{S}_{2}$, gerada em condições de alto grau, apresenta-se redobrado com atitudes do plano axial NW-SE (Basei et al 1992b).

O padrão geocronológico permite reconhecer terrenos antigos, formados no Paleoproterozóico, com idades isocrônicas $\mathrm{Rb}-\mathrm{Sr}$ em rocha total, e U-Pb em zircões no intervalo 2.720 $2.580 \mathrm{Ma}$ (Siga Jr., tese em preparação). As relações iniciais $\left(\mathrm{Sr}^{87} / \mathrm{Sr}^{86}\right)$ obtidas no intervalo 0,701-0,704 sugerem, adicionalmente, tratar-se de rochas oriundas do manto e/ou crosta inferior na época assinalada. Os dados $\mathrm{Sm} / \mathrm{Nd}$ (idades modelo $\mathrm{T}_{\mathrm{DM}}$ ) indicam dois intervalos principais de diferenciacão do manto dos precursores crustais desses gnaisses granulíticos. O primeiro, entre $2.800-2.700 \mathrm{Ma}$ (similar aos valores obtidos por meio de zircões e $\mathrm{Rb}-\mathrm{Sr}$, sugerindo evolução relativamente contínua no tocante à acresção/diferenciação); e o segundo, entre 3.100-3.000 Ma, sugerindo, nesse caso, maior tempo de residência crustal desses protolitos. 
Inúmeros diagramas, incluindo isócronas $\mathrm{Rb}-\mathrm{Sr}$ e $\mathrm{Pb}-\mathrm{Pb}$, em rocha total, U-Pb em zircões e $\mathrm{Sm}-\mathrm{Nd}$ em minerais, caracterizam a formação de rochas gnáissico-granulíticas, no final do Paleoproterozóico, Ciclo Transamazônico. O intervalo 2.250 - $1.850 \mathrm{Ma}$ representa esse período, e as relações iniciais $(0,701-0,708)$ sugerem acresção de material do manto ou retrabalhamento de crosta inferior nessa época. Os dados $\mathrm{Sm}-\mathrm{Nd}$ (idades modelo- $\mathrm{T}_{\mathrm{DM}}$ ) indicam o período 2.400 $2.200 \mathrm{Ma}$ como relativo à época em que os protolitos crustais dessas rochas se diferenciaram do manto.

$\mathrm{O}$ padrão $\mathrm{K}-\mathrm{Ar}$ obtido em diferentes minerais caracteriza o intervalo 2.100-1.700 Ma como o principal período de resfriamento desses terrenos. Valores superiores aos mencionados referem-se principalmente a análises obtidas em ultramafitos dos arredores de Barra Velha, com teores muito baixos em potássio, devendo, portanto, ser encarados com ressalva. Idades distribuídas entre 1.700-600 Ma foram obtidas principalmente próximas às zonas de borda, bem como no prolongamento norte deste cinturão de rochas granulíticas. Os dados obtidos devem retratar perdas parciais (idades intermediárias) ou mesmo totais (idades relativas ao Ciclo Brasiliano) de argônio, refletindo maior ou menor envolvimento tectono-termal desses terrenos frente à evolução brasiliana dos domínios adjacentes.

Domínio Curitiba Limita-se no setor noroeste com as sequências metavulcanossedimentares dos Grupos Açungui e Setuva e, a sudeste, com os gnaisses granulíticos do Domínio Luis Alves. Os contatos são feitos por importantes zonas de cisalhamento (empurrão), com indicações de sentido de movimento para SE, colocando as rochas pertencentes ao Cinturão Ribeira por sobre as do Domínio Curitiba, e estas por sobre as do Domínio Luis Alves.

Os terrenos deste domínio são caracterizados principalmente por gnaisses bandados, migmatíticos (mesossoma de biotita-anfibólio gnaisses e leucossoma de composição tonalito-granodiorítica); gnaisses graníticos bandados; leucogranitos foliados; biotita gnaisses lepidoblásticos; e anfibolitos (por vezes granatíferos). Adicionalmente, ocorrem xistos magnesianos, mangeritos, jotunitos, noritos foliados e rochas máfico-ultramáficas. Em termos mineralógicos, destaca-se nos gnaisses bandados a presença de hornblenda verde, normalmente poiquilítica, plagioclásio (albita- oligoclásio), quartzo, biotita (por vezes ausente) e, nos termos mais mesocráticos, podem ocorrer adicionalmente hiperstênio, diopsídio e granada. Os minerais acessórios comuns são allanita, titanita, zircão, apatita e opacos e, como produtos de alteração, ocorrem comumente epídoto, carbonato e clorita.

Os dados geocronológicos U-Pb (zircões), $\mathrm{Rb}-\mathrm{Sr}$ (rocha total e minerais) e Sm-Nd (minerais) caracterizam uma migmatização de idade brasiliana (620 - 550 Ma, Siga Jr., teseem preparação), cujos mobilizados brancos e róseos, finos a médios, até pegmatóides, foliados ou não, são os indicadores mais evidentes. As relações iniciais $\left(\mathrm{Sr}^{87} / \mathrm{Sr}^{86}\right)$ desses leucossomas distribuem-se no intervalo 0,713 a 0,716 , sugerindo tratar-se de rochas formadas no período assinalado, pelo retrabalhamento de materiais corri vida crustal anterior.

Os mesossomas preservam, notadamente em zircões, idades relativas ao Ciclo Transamazônico (2.150 - $1.800 \mathrm{Ma})$. Valores deste intervalo foram também obtidos em diagramas isocrônicos $\mathrm{Rb}-\mathrm{Sr}$, nos quais as relações iniciais $(0,703$ 0,710 ) indicam, em alguns casos, a presença de material oriundo do manto e/ou crosta inferior e, em outros, retrabalhamento de rochas de níveis crustais superiores. Os valores Sm-Nd (idades modelo $\mathrm{T}_{\mathrm{DM}}$ ) sugerem, para os protolitos dessas rochas, épocas relacionadas a diferenciações do manto durante o Arqueano e Paleoproterozóico.

A borda meridional deste domínio é balizada por granitóides cálcio-alcalinos deformados, de granulação média a grossa, em geral de cor rosada, e composição predominantemente monzogranítica (Fig. 1). São rochas atribuídas a raízes de provável arco magmático do Neoproterozóico (Machiavelli et al. 1991, Basei et al. 1992b). O limite tectônico desses terrenos com o domínio a sul (Domínio Luis Alves) é evidenciado por importante zona de cisalhamento, que coloca as rochas deste setor por sobre os granulitos da porção sul. Adicionalmente, nas proximidades desta zona limítrofe, ocorrem rochas ultramáficas serpentinizadas (regiões de Piên e Tijucas do Sul) admitidas sob o ponto de vista geotectônico, pêlos autores acima citados, como restos de assoalho oceânico obductado. Importante anomalia gravimétrica é caracterizada neste setor (Mantovani et al 1989).

Nesta porção, os dados geocronológicos disponíveis referem-se aos granitóides deformados que indicam idades entre $720(\mathrm{U}-\mathrm{Pb})$ e $580(\mathrm{Rb}-\mathrm{Sr}) \mathrm{Ma}$, para relações iniciais $\left(\mathrm{Sr}^{87} / \mathrm{Sr}^{86}\right)_{\mathrm{i}}$ entre 0,704 e 0,706. Os dados Sm-Nd (idades modelo - $\mathrm{T}_{\mathrm{DM}}$ ) apontam o intervalo 2.100-1.900 Ma (Ciclo Transamazônico) como o principal para a diferenciação manto/crosta de seus protolitos crustais.

Os dados K-Ar, obtidos em diferentes minerais, indicam, tanto para os granitóides deformados como para as rochas gnáissico-migmatíticas, padrão de resfriamento regional relativo ao Ciclo Brasiliano (640-520 Ma), caracterizando efeitos tectono-termais que atingiram o Cambriano Médio a Superior.

Estruturalmente, observa-se para as rochas do Domínio Curitiba orientação nordeste predominante. Essas superficies correspondem a uma segunda foliação, paralela ao bandamento nos gnaisses, e a uma primeira foliação nos granitóides deformados e ultramafitos de Piên. Verifica-se, na maioria das unidades do domínio, dobramento cilíndrico dessa foliação, com direções axiais NE-SW (Basei et al. 1992b).

Domínio Costeiro Grande parte da porção oriental da área estudada é representada por rochas graníticas porfiríticas cálcio-alcalinas, de granulação média a grossa, com megacristais de feldspatos (Fig. 1). Apresentam enclaves de composição diorítica com diferentes formas e tamanhos. Os megacristais são centimétricos, comumente zonados, localmente desenvolvendo estruturas do tipo augen.

Variações composicionais são frequentes, apresentando, como tipo mais comum, monzogranitos que contêm, em maior ou menor proporção, quartzo, plagioclásio, microclínio, biotita e/ou anfibólio. Entre os minerais acessórios destacam-se, opacos, zircão, apatita e titanita. Sericita e epídoto ocorrem comumente como alteração.

Os granitóides porfiríticos mostram-se por vezes intrudidos por granitóides leucocráticos, isótropos, que constituem pequenos stocks a corpos filonianos. São predominantemente leucogranitos a duas micas, ricos em feldspato potássico, plagioclásio e quartzo.

Como prováveis restos das rochas encaixantes, ocorrem xistos aluminosos, como os descritos na Serra do Prata por Lima \& Lopes (1985), biotita gnaisses, mica xistos, quartzitos e anfibolitos. Essas unidades podem apresentar-se migmatizadas em diferentes graus.

Faixas miloníticas espessas são frequentes em meio ao batolito granítico, principalmente nas bordas do mesmo, provavelmente ligadas a cavalgamentos com sentido de transporte para oeste, retomados tardiamente como transcorrências. Ao longo dessas, associa-se granitogênese mais jovem, exemplificada pelo Granito Rio Cubatãozinho (Lopes 1987).

O domínio Costeiro é marcado estruturalmente por orientação principal norte-nordeste e vergência voltada para oeste, rumo ao Domínio Luis Alves.

Os dados isocrônicos $\mathrm{Rb}-\mathrm{Sr}$ e U-Pb (em zircões) caracterizam a formação desses granitóides no Neoprote- 
rozóico, entre 615 e 570 Ma (Basei et al 1990, Siga Jr., tese em preparação). As idades modelo Sm-Nd ( $\left.\mathrm{T}_{\mathrm{DM}}\right)$ indicam, para os protolitos dessas rochas, o intervalo $2.250-1.900$ $\mathrm{Ma}$, caracterizando o Ciclo Transamazônico como o período em que os precursores desses granitóides foram adicionados à crosta. Os valores obtidos para o Nd, de-12a-16 (bastante negativos), são indicativos da longa residência crustal dos protolitos que deram origem ao domínio granítico discutido.

A investigação geocronológica realizada nessas rochas abrangeu adicionalmente análises isotópicas de $\mathrm{Pb}$, em felspatos potássicos, separados dos granitóides porfirfticos. $\mathrm{O}$ tratamento desses dados analíticos, segundo modelos de Plumbotectônica de Zartmam \& Doe (1981), sugere material oriundo, principalmente, de crosta inferior (Basei et al 1990), para a origem destes granitóides.

Os dados $\mathrm{K}-\mathrm{Ar}$ em biotitas distribuíram-se no intervalo 600-440 Ma, indicando que o período de resfriamento desses terrenos atingiu o Ordoviciano. Destaca-se que a maior concentração de idades K-Ar distribui-se no intervalo 540-480 Ma, sugerindo longo período de resfriamento do cinturão granitóide, desde sua formação até atingir temperaturas da ordem de $250^{\circ}-300^{\circ} \mathrm{C}$.

Maciços Graníticos e Vulcanismo Ácido-Intermediário Importante atividade plutônica, de características tardi a pós-tectônicas, é representada na área por inúmeros stocks e batolitos graníticos, notadamente de natureza alcalina a peralcalina (Suíte Serra do Mar, Kaul 1984). Nesse contexto, destacam-se os Maciços da Serra da Graciosa, Anhangava, Marumbi, Serra da Igreja, Agudos do Sul, Dona Francisca, Piraí do Sul, Corupá, e Morro Redondo. Normalmente, esses granitos mostram texturas granulares, hipidiomórficas, contendo, em maior ou menor proporção, quartzo, feldspato alcalino (muitas vezes pertítico a mesopertítico), plagioclásio, biotita, anfibólio (Ca$\mathrm{Na})$ e, mais raramente, clinopiroxênio ( $\mathrm{Na}-\mathrm{Ca})$ e faialita. Os minerais acessórios principais são titanita, zircão, apatita, opacos e, por vezes, fluorita. Como produtos de alteração, ocorrem normalmente carbonato, clorita, muscovita e epídoto.

Alguns maciços, a exemplo de Corupá e Morro Redondo, mostram variedades sienito-graníticas com tendências evolutivas desde metaluminosas até francamente peralcalinas. Nessa evolução, tem-se a presença de faialitas e clinopiroxênios (aegerina-augita), que se mostram, por vezes, bordejados por anfibólios cálcico-sódicos, até sódicos (riebeckita).

Foram realizados estudos radiométricos pêlos métodos $\mathrm{Rb}-\mathrm{Sr}$ (rocha total e minerais), U-Pb (zircões), $\mathrm{Sm}-\mathrm{Nd}$ ( $\left.\mathrm{T}_{\mathrm{DM}}\right)$ e K-Ar (minerais) em alguns desses maciços graníticos (Siga Jr., tese em preparação). As idades obtidas, bem como as relações iniciais, encontram-se resumidas na tabela 1 .

Esses dados permitem caracterizar o intervalo 600 - 550 Ma como o que melhor representa o período de colocação desses corpos. As idades modelo Sm-Nd $\left(\mathrm{T}_{\mathrm{DM}}\right)$ caracterizam épocas transamazônicas e pré-transamazônicas para os protolitos crustais dessas rochas.

$\mathrm{O}$ intervalo 585-520 Ma representa o período principal de resfriamento dos maciços graníticos, evidenciado pêlos dados K-Ar obtidos em minerais.

Esses maciços graníticos apresentam-se intrusivos nos Terrenos Luis Alves e Curitiba. Além disso, as idades de formação desses corpos $(600$ - $550 \mathrm{Ma})$ mostram-se bastante próximas dos valores obtidos para o fechamento do sistema Rb-Sr da porção oriental estudada (615 - $570 \mathrm{Ma})$, sugerindo origem relacionada à evolução desse Domínio Costeiro.

Importantes sequências vulcanossedimentares ocorrem na região estudada, representadas pelas Bacias Molássicas de Campo Alegre, Guaratubinha e Corupá. Nessas bacias intercalam-se, em proporções variadas, rochas sedimentares, vulcanoclásticas e vulcânicas ácidas a intermediárias. Os dados $\mathrm{Rb}-\mathrm{Sr}$, em rocha total, relativos a riolitos da Bacia de Campo Alegre indicam, em diagrama isocrônico, idade Üe $497 \pm 13 \mathrm{Ma}$, para uma relação inicial de 0,708. Os valores relativos a colocação dessas rochas, obtidos pêlos dados U-Pb em zircões, distribuíram-se entre 480 e 455 Ma (Siga Jr., tese em preparação).

Trata-se, portanto, de importante atividade vulcânica, com sedimentação associada, de idade pré-cambriana, provavelmente relacionada a fases distensivas, tardias à evolução principal dos terrenos estudados.

IMPLICAÇÕES TECTÔNICAS A compartimentação tectônica, hoje observada para o setor NE de Santa Catarina e SE do Paraná, foi produzida por diversos processos geológicos, cujos registros estão impressos na natureza polifásica e policíclica de grande parte das rochas que aí ocorrem. Os estudos efetuados permitiram comprovar a existência de três compartimentos geotectônicos distintos: Domínio Luis Alves, Domínio Curitiba e Domínio Costeiro (Fig. 1).

O Domínio Luis Alves é representado por terrenos que permaneceram frios durante o Ciclo Brasiliano, sendo afetados termicamente (parcial ou totalmente, principalmente as biotitas) somente em parte de seu prolongamento norte e próximo às zonas de contato com os domínios adjacentes. A história evolutiva desses terrenos granulíticos remonta ao Arqueano (2.720 - $2.580 \mathrm{Ma})$ e ao Paleoproterozóico $(2.250$ - $1.850 \mathrm{Ma})$, Ciclo Transamazônico, épocas essas relacionadas à formação dessas rochas por meio de proces-

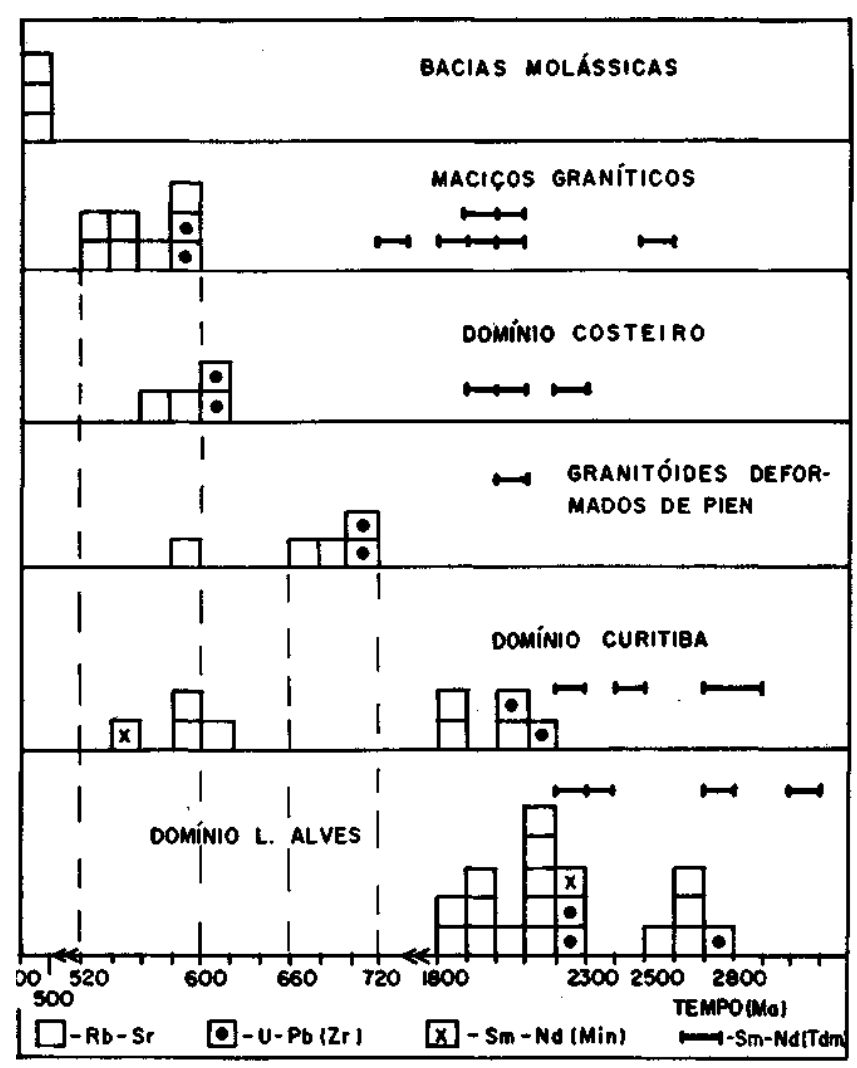

Figura 2 - Histograma de idades $\mathrm{Rb}-\mathrm{Sr}$, U-Pb (zircões) e $S m-N d\left(T_{D M}\right)$ para os terrenos localizados no setor $S E$ do Paraná e NE de Santa Catarina

Figure 2 - Histogram of $\mathrm{Rb}-\mathrm{Sr}, \mathrm{U}-\mathrm{Pb}$ (zircon) and $\mathrm{Sm}-\mathrm{Nd}$ $\left(\mathrm{T}_{\mathrm{DM}}\right)$ radiometric ages for the studied área 
Tabela 1 - Dados geocronológicos dos maciços graníticos da porção SE do Paraná e NE de Santa Catarina Table 1 - Geochronological data for the alkaline-peralkaline granitoids (SE/Paraná - NE/Santa Catarina)

\begin{tabular}{l|l|l|l|l|l|l|l}
\hline $\begin{array}{l}\text { MACICOS } \\
\text { METODOS }\end{array}$ & $\begin{array}{l}\text { AGUDOS } \\
\text { DO SUL }\end{array}$ & ANHANGAVA & CORUPÁ & GRACIOSA & $\begin{array}{l}\text { MORRO } \\
\text { REDONDO }\end{array}$ & ESTRELA & $\begin{array}{l}\text { VULCÂNICAS } \\
\text { CAMPO ALEGRE }\end{array}$ \\
\hline $\begin{array}{l}\text { Rb/Sr } \\
\text { ISÓCRONA } \\
\text { (Ri) }\end{array}$ & $\begin{array}{l}570 \pm 22 \\
(0,7073)\end{array}$ & $\begin{array}{l}557 \pm 60 \\
(0,7309)\end{array}$ & $\begin{array}{l}550 \pm 26 \\
(0,7070) \\
481+l-32\end{array}$ & $\begin{array}{l}584 \pm 12 \\
(0,7080) \\
(0,7064)\end{array}$ & $\begin{array}{l}590-525 \\
(0,706-0,720)\end{array}$ & $\begin{array}{l}520 \pm 30 \\
(0,708)\end{array}$ & $\begin{array}{l}497 \pm 13 \\
(0,708)\end{array}$ \\
\hline $\begin{array}{l}\text { U/Pb } \\
\text { (zircðes) }\end{array}$ & $594 \pm 26$ & & $580 \pm 6$ & $594 \pm 64$ & $589 \pm 37$ & & $608 \pm 10$ \\
\hline Sm/Nd (TDM) & 3.650 & 1.850 & 1.940 & & 1.980 & 2.570 & \\
\hline $\begin{array}{l}\text { K/Ar } \\
\text { (minerais) }\end{array}$ & $580-540$ & aprox.550 & $535-525$ & $585-520$ & aprox. 565 & aprox 540 & $480-455$ \\
\hline
\end{tabular}

sós de acresções/diferenciações de material do manto e/ou crosta inferior (Fig. 2). No Neoproterozóico, esses terrenos não atingiram, em sua maior parte, a isoterma de $250^{\circ} \mathrm{C}$ (K-Ar em biotitas entre $2.100-1.700 \mathrm{Ma}$ ). Trata-se da porção continental de uma microplaca que estaria localizada entre os Crátons do Congo (África) e do Paraná (Brasil), durante o Neoproterozóico. A caracterização de seu prolongamento para norte, em direção ao Maciço Serra Negra, revela que as dimensões desta Microplaca deveriam ser bem maiores, com continuidade até as rochas granulíticas pertencentes ao Maciço de Itatins, já no sudeste de São Paulo.

Os terrenos a norte, relativos ao Domínio Curitiba, mostram características geológicas, geocronológicas e estruturais distintas daqueles pertencentes ao Domínio Luis Alves. Embora esse domínio preserve registros evolutivos do $\mathrm{Pa}-$ leoproterozóico (2.150-1.800 Ma), Ciclo Transamazônico, a principal fase de migmatização/granitização ocorreu durante o Ciclo Brasiliano (620 - 550 Ma, Fig. 2). Acrescenta-se que os valores obtidos pelas análises K-Ar, em hornblendas, biotitas e plagioclásios, caracterizam para o metamorfismo da fácies anfibolito, idade brasiliana (640 - $520 \mathrm{Ma}$, Fig. 3). $\mathrm{O}$ trena estrutural nordeste difere do padrão observado no Domínio Luis Alves, francamente noroeste, sendo o contato entre esses domínios marcado em grande parte por granitóides cálcio-alcalinos formados no Neoproterozóico (720 $580 \mathrm{Ma})$.

Basei et al. (1992b) individualizam esses terrenos setentrionais como pertencentes a uma microplaca (Microplaca Curitiba). Admitem processos de subducções e colisões no Neoproterozóico e no Cambriano, que causariam a justaposição da Microplaca Curitiba e do Cráton do Paraná, por debaixo do Cinturão Ribeira. A seguir, a colisão entre as Microplacas Luis Alves e Curitiba, com fechamento do oceano existente entre elas, seria decorrência da movimentação desses terrenos para nordeste.

Geotectonicamente, parece plausível caracterizar os terrenos Curitiba como integrantes de microplaca distinta da Luis Alves. Alguns aspectos, no entanto, a exemplo da ausência de metassedimentos relacionados à evolução do suposto oceano brasiliano, existente entre essas microplacas, necessitam de pesquisas adicionais, uma vez que o metamorfismo impresso nos granitóides associados ao arco magmático e nas ultramáficas (prováveis restos de um fundo oceânico) são da fácies xisto verde. Do mesmo modo, estudos complementares devem ser realizados nas rochas máfico-ultramáficas, numa tentativa de melhor esclarecer aspectos relacionados a seu significado geotectônico.

As investigações, recentemente realizadas neste setor, principalmente no campo da geocronologia (Siga Jr., tese em preparação), permitiram sugerir um modelo evolutivo alternativo. Nesse modelo, os terrenos pertencentes ao Do-

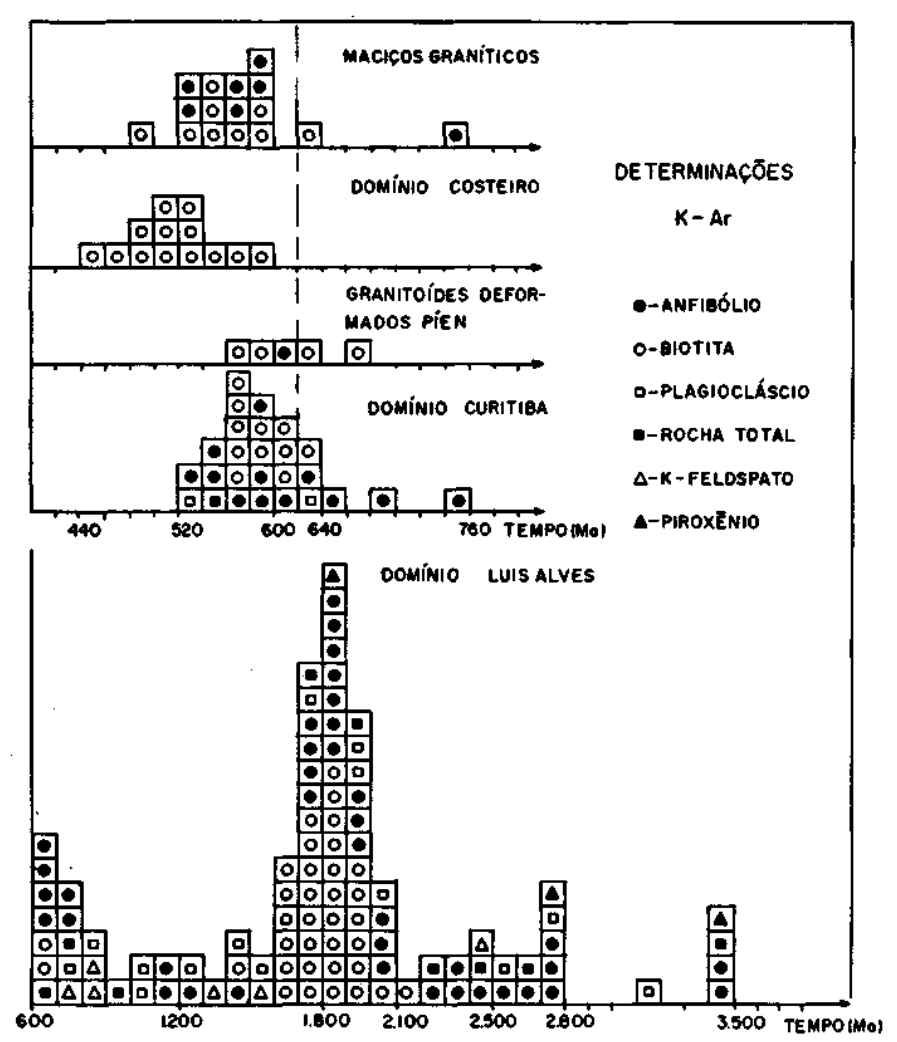

Figura 3 - Histograma de idades K-Ar para os terrenos localizados no setor SE do Paraná e NE de Santa Catarina Figure 3 - Histogram of K-Ar cooling ages for the studied área

mínio Curitiba não representariam uma microplaca e sim a margem nordeste da Microplaca Luis Alves, envolvida pela tectônica brasiliana, reflexo de sua colisão contra o Cráton do Paraná. Tratar-se-ia de zona de borda, intensamente deformada, migmatizada e granitizada, em decorrência de tectônica controlada principalmente por falhamentos de empurrão. Nesse contexto, estariam atualmente expostas, nesse domínio, rochas profundas da fácies anfibolito, ao lado de níveis relativamente mais rasos, da fácies xisto verde, bem como porções pouco afetadas, preservadas dessa tectônica, que colocaria, lado a lado, blocos de distintos níveis crustais.

Do ponto de vista geocronológico, a presença de rochas granulíticas, a norte de Curitiba, com idades (inclusive pelo método K-Ar), relativas ao Ciclo Transamazônico $(\sim 1.800$ $\mathrm{Ma}$ ), ao lado de porções granito-gnáissicas, migmatíticas, 
formadas no Ciclo Brasiliano, favorecem a hipótese mencionada (Fig. 4).

$\mathrm{O}$ padrão $\mathrm{Sm}-\mathrm{Nd}$ (idades modelo $\mathrm{T}_{\mathrm{DM}}$ ), relacionado a épocas de diferenciação do manto, dos protolitos crustais, mostra-se coerente com aquele observado para o Domínio Luís Alves, caracterizando idades do intervalo 2.800 - 2.700 Ma e 2.400 - 2.200 Ma (Fig. 2).

Os dados U-Pb (zircões) e $\mathrm{Rb}-\mathrm{Sr}$ (rocha total) preservam, notadamente nos mesossomas de migmatitos, idades rela-

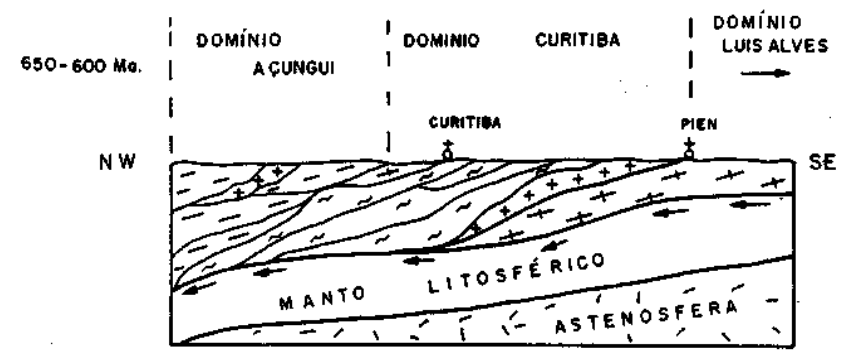

Figura 4-Colisão da Microplaca Luís Alves com áreas cratônicas a NW

Figure 4 - Collision between the Luis Alves Microplate and the NW cratonic área cionadas ao Ciclo Transamazônico $(2.150-1.800 \mathrm{Ma})$, enquanto os leucossomas são claramente formados no Ciclo Brasiliano (620-550 Ma).

Adicionalmente, o diagrama de evolução das razões $\mathrm{Sr}^{87} / \mathrm{Sr}^{86}$, no tempo geológico, permite tecer inferências de derivação desses terrenos gnáissico-migmatíticos, a partir dos representantes dos Granulitos Luis Alves (Fig. 5). Isto, deve-se ao posicionamento das relações iniciais das rochas do Domínio Curitiba, internamente ao leque evolutivo Luis Alves.

Os granitóides foliados, pertencentes ao Domínio Costeiro, apresentam idades de formação relativas ao Neoproterozóico, entre 615 e $570 \mathrm{Ma}$; para seus protolitos crustais (épocas de derivação do manto), valores do Paleoproterozóico (Ciclo Transamazônico), conforme dados Sm-Nd (idades modelo $\mathrm{T}_{\mathrm{DM}}$ ) entre $2.250 \mathrm{e} 1.900 \mathrm{Ma}$ (Fig. 2).

As figuras 2 e 6 permitem uma comparação entre o padrão geocronológico dos terrenos do Cinturão Costeiro e aqueles do Domínio Curitiba. Neste sentido, observa-se que o intervalo de idade $\mathrm{Rb}-\mathrm{Sr}$ e U-Pb (zircões), relacionado ao Neoproterozóico, é bastante similar para os dois domínios discutidos. Tais dados sugerem que nessa época predominava regime tectônico compressivo nos terrenos pertencentes ao Domínio Curitiba (idades $\mathrm{Rb}-\mathrm{Sr}$, relacionadas ao metamorfismo dessas rochas), enquanto no Cinturão

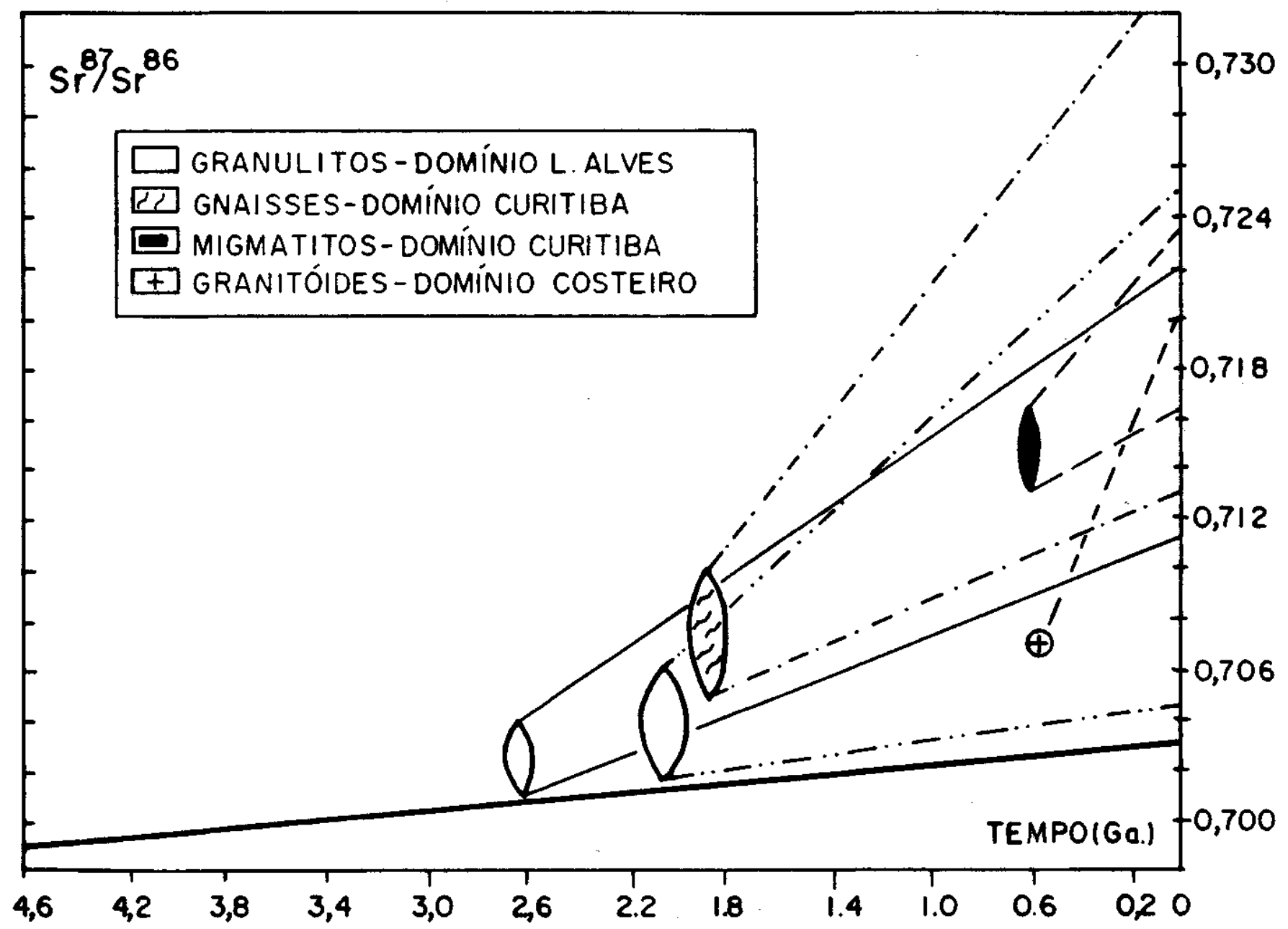

Figura 5 - Diagrama de evolução da relação $\mathrm{Sr}^{87} / \mathrm{Sr}^{86}$, no tempo, para as rochas da porção SE do Paraná e NE de Santa Catarina

Figure $5-\mathrm{Sr}^{87} / \mathrm{Sr}^{86} v$ s. time (Ga) diagram for SE Paraná - NE Santa Catarina 


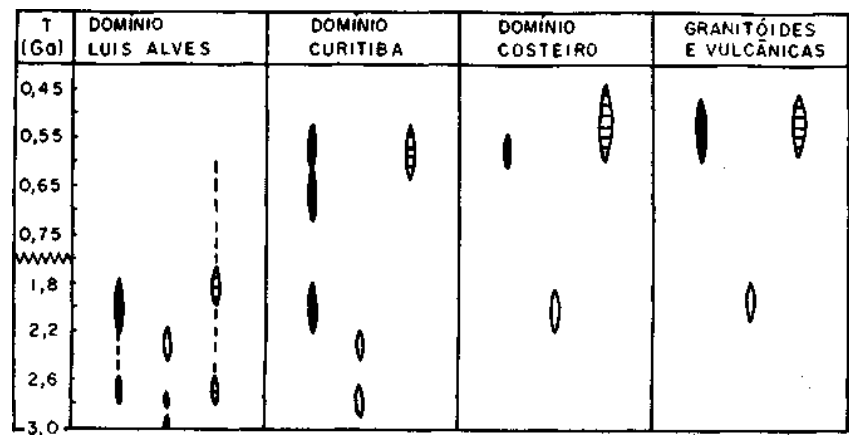

Figura 6 - Principais épocas de formação (Rb-Sr; U-Pb; Sm-Nd-min. - em negrito), acresção (Sm-Nd-T $T_{D M}$ - vazio), e resfriamento ( $K-A r$ - traços horizontais) dos terrenos localizados na porção SE do Paraná e NE de Santa Catarina Figure 6 - Main rock formation times (Rb-Sr; U-Pb; and mineral $\mathrm{Sm}-\mathrm{Nd}$ ages - in black), mantle-crust differentiation (Sm-Nd model ages - open) and cooling ages (mineral K-Ar data - horizontal lines) for SE Paraná - NE Santa Catarina terranes

Costeiro ainda ocorria a colocação dos granitóides cálcioalcalinos (idades U-Pb e Rb-Sr, relacionadas à formação dessas rochas).

- A aplicação do método K-Ar em rochas pertencentes aos diferentes domínios estudados permitiu, não só caracterizar com precisão o padrão de resfriamento regional desses terrenos, mas também possibilitou tecer inferências sobre a tectônica que atuou na justaposição dos mesmos. Com este objetivo, foram confeccionados perfis K/Ar (térmicos), que seccionaram transversalmente os contatos entre os diferentes setores estudados (Figs. 7 e 8). Observa-se padrão semelhante nos trechos Curitiba-Paranaguá (E-W, Fig. 7) e Curitiba-São Bento do Sul (N-S, Fig. 8), no tocante aos limites tectônicos entre os terrenos Curitiba e Luis Alves. A importância do evento tectono-termal brasiliano, que atingiu as rochas pertencentes ao Domínio Curitiba, é evidenciada através do patamar de idades entre 640 e 520 Ma. A passagem desses terrenos para os pertencentes ao Domínio Luis Alves é marcada por tendência de aumento gradativo das idades K-Ar rumo a este último domínio, até atingir outro patamar relativo ao Ciclo Transamazônico (2.100 - $1.700 \mathrm{Ma})$. O contato oriental, com o Cinturão Costeiro, mostra comportamento diferente, ocorrendo salto das idades transamazônicas, representantes do Domínio Luis Alves a valores do intervalo 600 - $440 \mathrm{Ma}$ (Fig. 7). As diferenças térmicas observadas nos limites desses terrenos são interpretadas como resultantes de superposições distintas dos mesmos. Assim, o limite norte sugere envolvimento térmico expressivo e gradativo entre os terrenos Curitiba e Luis Alves, distinto do indicado para o setor sul oriental, onde a justaposição parece ter ocorrido a temperaturas mais baixas.

- Após a justaposição desses blocos, ocorreu importante granitogênese de natureza alcalina-peralcalina, representada pêlos inúmeros stocks e batolitos graníticos no âmbito dos domínios estudados.

Observa-se que os valores isocrônicos $\mathrm{Rb}-\mathrm{Sr}$, relativos ao Domínio Costeiro, mostram-se bastante similares às épocas de cristalização dos zircões nos maciços graníticos (Fig. 2). Tal padrão indica certa sincronia entre a formação dessas rochas graníticas e a colisão dos Domínios Costeiro e Luis Alves. Os dados K-Ar revelam, ainda, que o Domínio

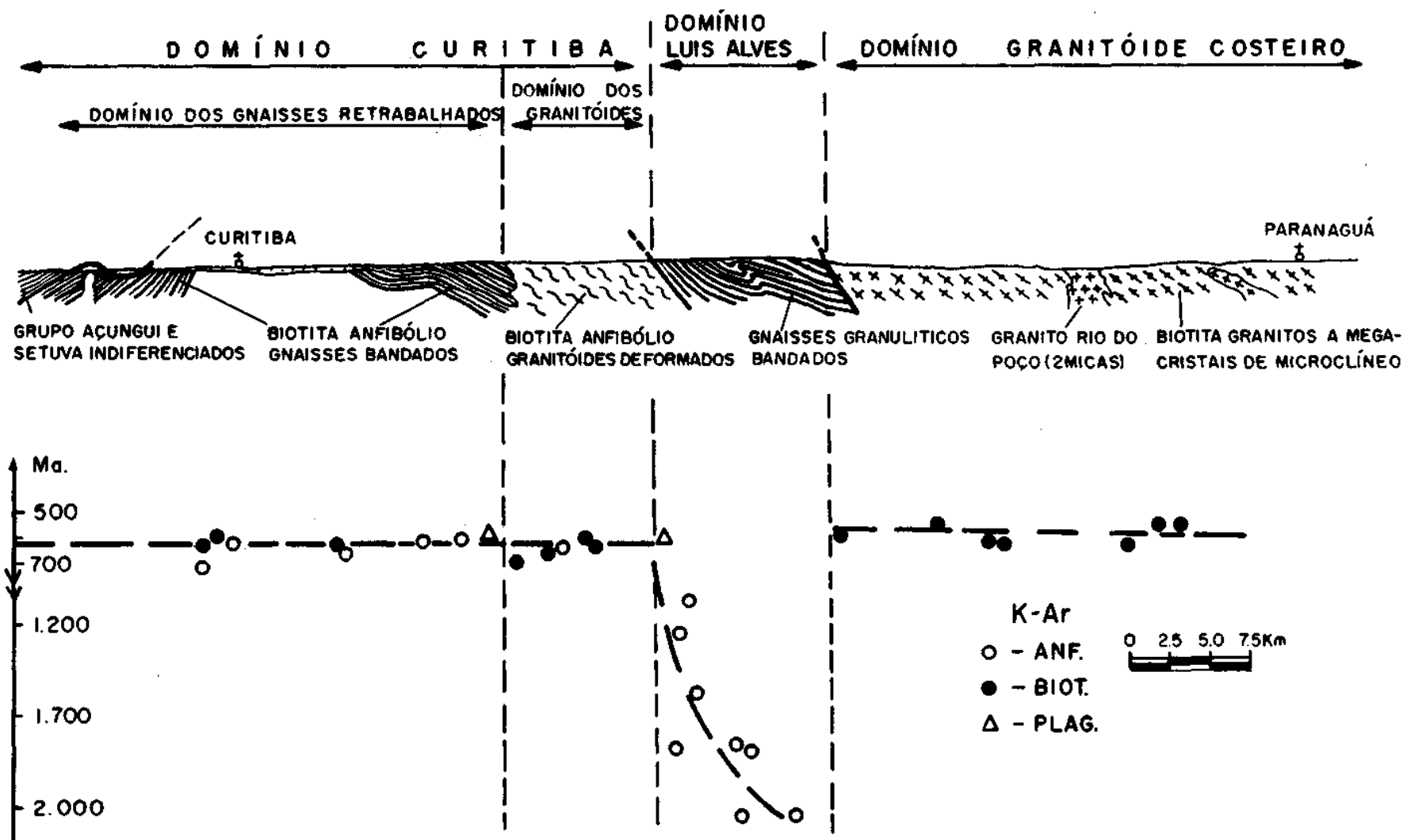

Figura 7 - Perfil K-Ar do trecho Curitiba-Paranaguá Figure 7 -K-Ar cooling curves for the Curitiba - Paranaguá profile 

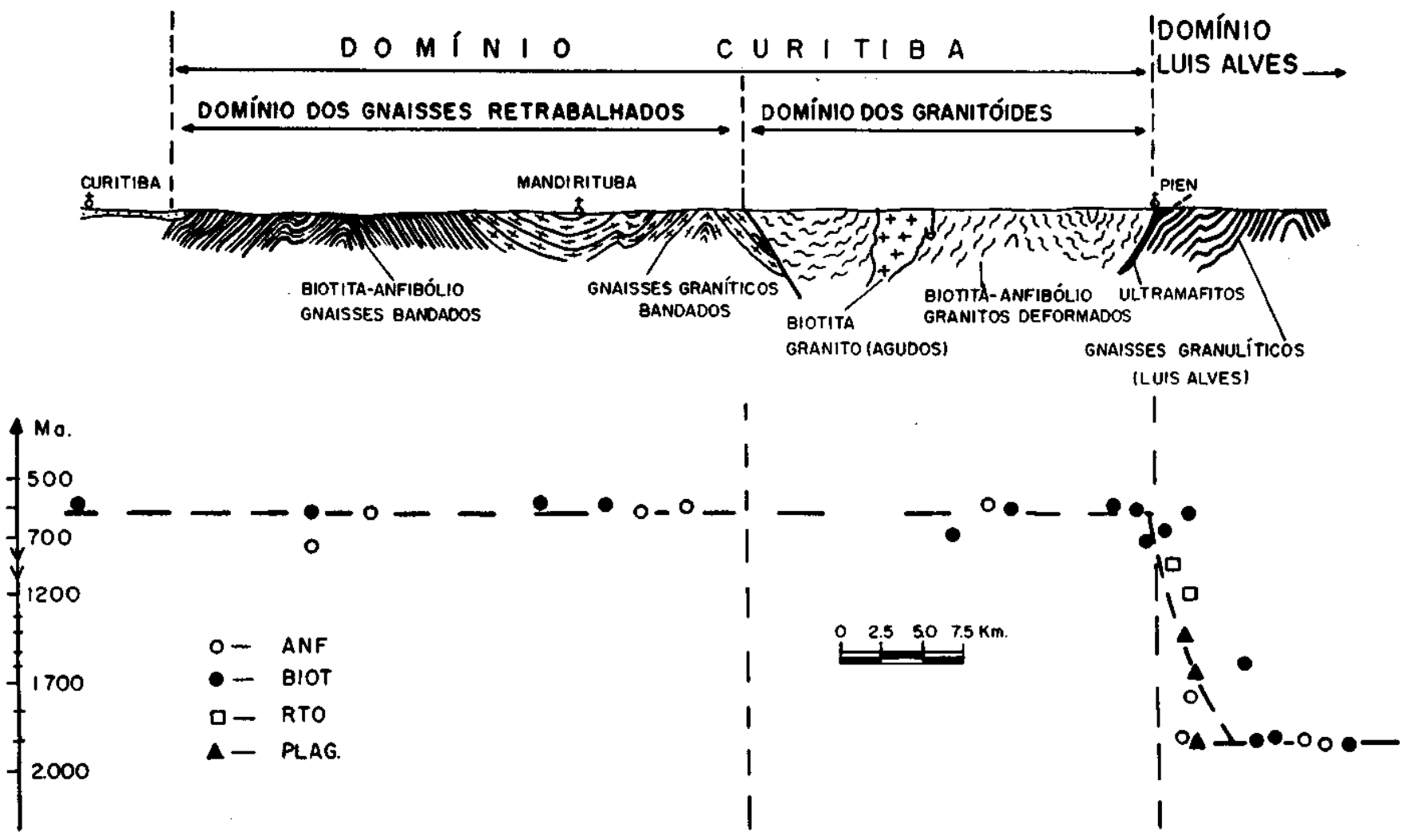

Figura 8 - Perfil K-Ar do trecho Curitiba - São Bento do Sul Figure 8 -K-Ar cooling curves for the Curitiba - São Bento do Sul profile

Costeiro permaneceu quente (isotermas no intervalo $250^{\circ}$ $300^{\circ} \mathrm{C}$ ) por mais tempo que os domínios adjacentes, incluindo os granitóides intrusivos (Fig. 3). - Finalmente, expressivo vulcanismo ácido a intermediário de idade cambriana ocorre na região, associado às Bacias Molássicas de Campo Alegre, Guaratubinha e Corupá.
Tais manifestações refletem, nesta época (520-480 Ma) regimes tectônicos distensivos, consequência do rearranjo crustal, decorrente do espessamento litosférico produzido pelas colisões continentais que ocorreram no final do Neoproterozóico.

\section{REFERÊNCIAS BIBLIOGRÁFICAS}

BASEI, M.A.S. 1985. O Cinturão Dom Feliciano em Santa Catarina. São Paulo. $190 \mathrm{p}$. (Tese de Doutoramento, IG-USP).

BASEI, M.A.S.; SIGA JÚNIÇR, O.; REIS NETO, J.M. 1990. O Batolitp Paranaguá. Proposição, idade, considerações petrogenéticas e implicações tectônicas. In: CONGR. BRAS. GEOL., 36. Natal, 1990. Anais . Natal, SBG. v. 4, p. 1684-1699.

BASEI, M.A.S.; SIGA JÚNIOR, O.; MACHIAVELLI, A.; MANCINI, F. 1991. Evolução tectônica do Maciço de Joinville (PR - SC). In: SIMP. NAC. EST. TECT, 3. Rio Claro, 1991. Boletim... Rio Claro, SBG. v. 1.p.132-133.

BASEI, M.A.S.; SIGA JÚNIOR, O.; MACHIAVELLI, A. 1992a. Tectônica de nappes do Proterozóico Superior e Eopaleozóico da porção sul-brasileira. In: TOSELLI, J. ed. El paleozóico inferior en latinoamerica y Ia génesis dei Gondwana. Tucuman, Universidad Nacional de Tucuman p. 215-217. (Série Correlacion Geológica 9).

BASEI, M.A.S.; SIGA JÚNIOR, O.; MACHIAVELLI, A.; MANCINI, F. 1992b. Evolução tectônica dos terrenos entre os Cinturões Ribeira e Dom Feliciano (PR - SC). Rev. Brás. Geoc., 22(2):216-221.

BIONDI, J.C.; CAVA, L.T.; SOARES, P.C. 1989. Mapa Geológico do Estado do Paraná - Escala 1:650.000. Curitiba, DNPM MINEROPAR

CARNEIRO, C.D.R. 1974. Esboço e diferenciação tectônica do précambriano superior no sul-sudeste do Brasil. In: CONGR. BRÁS. GEOL., 28. Porto Alegre, 1974. Resumo das Comunicações... Camboriú, SBG. Boi. 1, p. 698-700.

CONDIE, K.C. 1989. Plate Tectonics and Crustal Evolution. 3 ed. Oxford, Pergamon. $476 \mathrm{p}$.

CORDANI, U.G. \& GIRARDI, VA.V. 1967. Geologia da Folha de Morretes. Boi. Paraná. Geociênc. 26:26-40. (Série Geologia).

FRAGOSO CESAR, A.R.S. 1991. Tectônica de Placas no Ciclo Brasiliano: As Orogenias dos Cinturões Dom Feliciano e Ribeira no
Rio Grande do Sul. São Paulo. 367 p. (Tese de Doutorado, IG-USP)

FUCK, R.A.; TREIN, E.; MURATORI, A.; RIVEREAU, I.C. 1969. Mapa geológico preliminar do litoral, da Serra do Mar e parte do primeiro planalto do Estado do Paraná. Boi. Paraná Geociênc. 27:123-152.

GIRARDI, V.A.V. 1974. Petrologia do Complexo Básico-Ultrabásico de Piên •PR. São Paulo. 146 p. (Tese de Livre Docência, IG-USP).

HARTMANN, L.A.; SILVA, L.C.; ORLANDI FILHO, V. 1979. O Complexo Granulítico de Santa Catarina. Descrição e Implicações Genéticas. Acta Geol. Leopold., 6:93-112.

HASUI Y; CARNEIRO, C.D.R · COIMBRA, A.M. 1975. The Ribeira Folded Belt. Rev. Brás. Geoc., 5(4):257-266.

KAUL, P.F.T. 1984. Significado dos granitos anorogênicos da Suíte Intrusiva Serra do Mar na evolução da crosta do sul-sudeste do Brasil, no âmbito das Folhas SG-22-Curitiba e SG-23-Iguape. In: CONGR. BRÁS. GEOL., 33. Rio de Janeiro, 1984. Anais... Rio de Janeiro, SBG. v. 6, p. 2815-2825.

KAUL, P.F.T. 1985. Magmatismo e evolução da crosta no sul-sudeste do Brasil, durante o Proterozóico Superior e Eopaleozóico. In: SIMP. SUL-BRAS. GEOL., 2. Florianópolis, 1985. Atas... Florianópolis, SBG p. 126-127.

KAUL, P.F.T. \& TEIXEIRA, W. 1982. Archean and Early Proterozoic Complexes of Santa Catarina, Paraná and São Paulo States, SouthSoutheastem, Brazil: an outline of their geological evolution. Rev. Brás. Geoc., 12(1/3):172-182.

LIMA, Q.E. \& LOPES, O.F. 1985. Evolução geológica da Formação Rio das Cobras no leste do Estado do Paraná. In: SIMP. SUL-BRAS. GEOL., 2. Florianópolis, 1985. Atas... Florianópolis, SBG. p. 53-60.

LOPES, O.F. 1987.0 Granito Sin-Tectônico Cubatãozinho: petrogenese e evolução geológica. In: SIMP. SUL-BRAS. GEOL., 3. Curitiba, 1987. Atas... Curitiba, SBG. v. 2, p. 481-490. 